\title{
A solitary penile lesion
}

Cong Sun, Jim Muir

\section{CASE \\ A man aged 73 years presented for a routine full skin examination and reported a new erythematous lesion, which occasionally bled, on the dorsal shaft of the penis. On examination, there was a well-circumscribed, erythematous scaling papule with superficial erosion on the dorsal shaft (Figure 1).}

\section{QUESTION 1}

What are the differential diagnoses for this lesion?

\section{QUESTION 2}

What additional clinical features should be sought on history and examination to differentiate the possible diagnosis?

\section{ANSWER 1}

The differential diagnoses for this lesion include a variety of aetiologies such as infective, inflammatory and neoplastic. ${ }^{1,2}$ Penile lesions caused by infections include genital warts, primary syphilitic chancres, genital herpes and scabies nodules. Inflammatory dermatoses such as psoriasis or lichen planus are also possible..$^{2,3}$ Neoplastic entities to be considered include Bowen's disease, bowenoid papulosis, erythroplasia of Queyrat and the less likely possibility of invasive squamous cell carcinoma. ${ }^{3}$

\section{ANSWER 2}

The pertinent history and features on examination are included in Table 1.

\section{CASE CONTINUED}

The patient stated that the lesion had been present for 3-4 months and caused no additional symptoms other than occasional bleeding. He had neither personal nor familial history of any inflammatory skin conditions but had a history of numerous skin malignancies including lentigo maligna, basal and squamous cell carcinoma. This was the patient's first penile lesion. There was no history of vesicular or warty lesions on or around the genitals. Full skin examination revealed no other lesions on his skin or mucosal surfaces. In particular, the oral mucosa, perianal skin, webbing of the fingers and intertriginous areas were clear. There was no regional lymphadenopathy. The patient was in a long-term heterosexual relationship with no recent change in sexual partners. Dermoscopy of the penile lesion showed an erythematous background with areas of hyperkeratotic scaling, superficial erosion and numerous glomerular vessels (Figure 2).

\section{QUESTION 3}

What is the most likely diagnosis? Is biopsy indicated?

\section{ANSWER 3}

The history and clinical appearance of this penile lesion are highly concerning for a neoplastic process, in particular some form of intraepidermal carcinoma. Glomerular vessels, which are dilated tortuous vessels in the dermal papillae that align perpendicular to the skin surface producing a doted appearance on dermoscopy, are a non-specific but common feature of intraepidermal carcinoma. Penile biopsies/procedures can be performed readily with a low rate of complications under local anaesthetic. The common methods of local anaesthesia include topical anaesthetic cream, local infiltration or dorsal penile nerve block. ${ }^{4-6}$ Adrenaline can be safely used in penile procedures in the office setting. ${ }^{7}$ Similar to cutaneous biopsy of other regions of the body, a variety of techniques such as shave, punch, incisional or excisional biopsy can be used.

\section{CASE CONTINUED}

A shave biopsy after local infiltration with $1 \%$ plain lignocaine was performed. The operator used plain lignocaine as they were confident in achieving haemostasis.

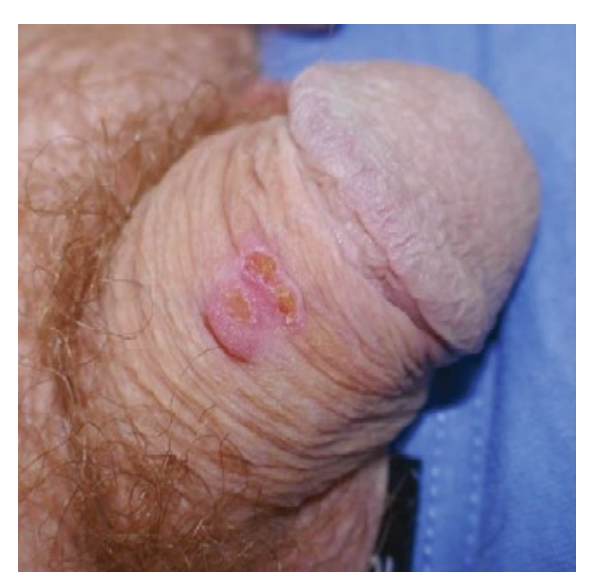

Figure 1. Dorsal penile lesion of a man aged 73 years 
A shave allowed sampling across the lesion into the underlying dermis, minimising sampling error.

The histology of the shave biopsy was reported to be consistent with a diagnosis of bowenoid papulosis (Figure 3). There was no evidence of invasion. No further investigations were performed as the biopsy ruled out other differentials.

\section{Table 1. Differential diagnosis of penile lesions and their pertinent clinical features}

\section{Differential diagnosis for}

erythematous penile lesion Distinguishing clinical features

$\begin{array}{ll}\begin{array}{l}\text { Bowen's disease/bowenoid } \\ \text { papulosis/erythroplasia of } \\ \text { Queyrat }\end{array} & \text { - Often solitary lesions } \\ & \text { - Usually asymptomatic but can cause pruritus, pain, } \\ & \text { - Most commonly associated with human papillomavirus } \\ & \text { - HPV) } 16 \text { and } 18 \text { infections } \\ & \text { Tend to occur in elderly individuals, with frequency } \\ \text { increasing with age } & \text { Dermoscopy may show dotted and glomerular vessels, } \\ & \text { as seen in intraepidermal carcinomas of other sites of the } \\ & \text { body }\end{array}$

- Patients often have similar lesions in the intertriginous
areas of the body; however, penile lesions can be the sole
manifestation
- Associated with silvery, superficial scales
- Lesions are often pruritic

\begin{tabular}{|c|c|}
\hline Lichen planus & $\begin{array}{l}\text { - Violaceous and intensely pruritic lesions } \\
\text { - Most commonly affect the glans penis } \\
\text { - Fine white streaks can be found on the surface of the } \\
\text { lesions (Wickham's striae) } \\
\text { - Can be associated with lesions of other sites including } \\
\text { similar oral lesions }\end{array}$ \\
\hline
\end{tabular}

Genital herpes - Primary infection may be accompanied by fever, myalgia and lethargy

- Lesions are usually grouped vesicles with a tendency to cause painful ulceration

- Recurrence is common after primary infection

- Acute onset with gradual resolution within 2-3 weeks

Condyloma acuminata - Often difficult to treat and marked by the predilection for recurrence

- Manifest as dome-shaped, usually flesh-coloured papules coalescing to form a verrucous appearance

- May also occur in the perianal region

Primary syphilitic chancre

- History of recent change in sexual partner

- May be associated with non-tender lymphadenopathy

- Single painless, indurated, firm and ulcerated lesion, usually on the glans

- Ulcer usually heals within several weeks without treatment

Scabies infestation

- Associated with lesions in other parts of the body - namely the web spaces of the fingers, axillae and the flexor surfaces of the wrist

- Scabies nodules on the genitals are intensely pruritic and often present with multiple lesions
The pathologist reported full-depth cellular atypia in the epidermis with no invasive component found. Correlating the histology of the biopsy and the clinical context, a diagnosis of bowenoid papulosis was made.

\section{QUESTION 4}

What is bowenoid papulosis?

\section{QUESTION 5}

What are the treatment options?

\section{ANSWER 4}

Bowenoid papulosis is a pre-malignant condition associated with human papillomavirus (HPV), namely the highly carcinogenic strains HPV 16 and $18 .^{1}$ Bowenoid papulosis involves the mucosal surface of the glans, while Bowen's disease

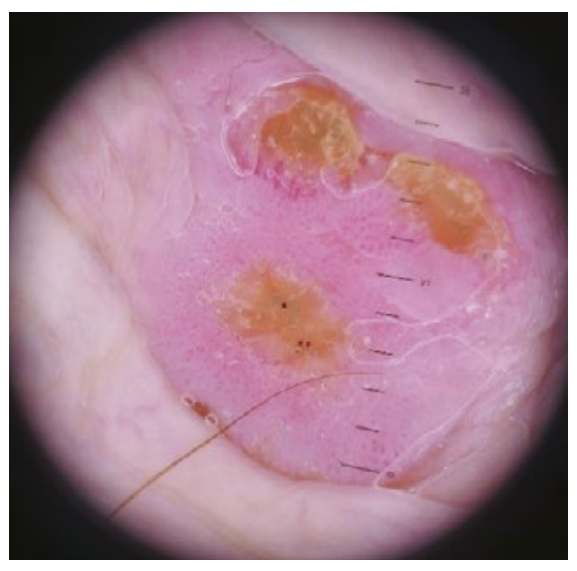

Figure 2. Dermoscopic image of the penile lesion

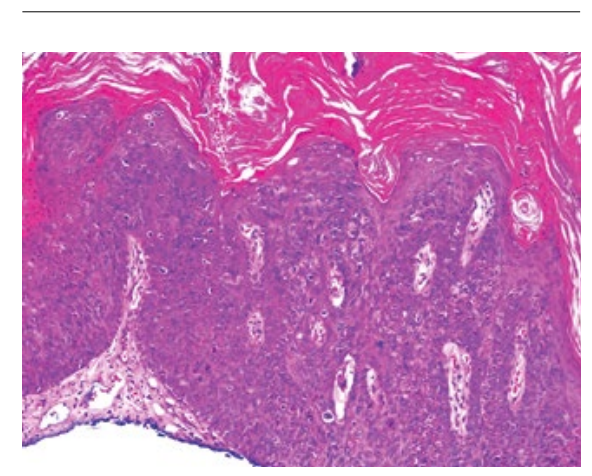

Figure 3. Histopathology of the penile biopsy 
and erythroplasia of Queyrat - which are also HPV-associated premalignant lesions - are found mostly on the shaft or prepuce. ${ }^{1}$

Bowenoid papulosis tends to be verrucous/warty. The lesions can become eroded and crusted. Bowenoid papulosis has a very low rate of malignant transformation in general and when compared with Bowen's disease and erythroplasia of Queyrat, but transformation rates can be higher when the patient is immunosuppressed. ${ }^{1,8}$

As bowenoid papulosis is a wart virusrelated malignancy, the patient's contacts should have appropriate cervical screening to determine the status of infection.

\section{ANSWER 5}

The treatment options for this lesion include cryotherapy, topical 5-fluorouracil, imiquimod, ablative laser therapy, photodynamic therapy and surgery (excision, or curettage and cautery) ${ }^{1}$

\section{CASE CONTINUED}

Curettage and cautery was the treatment modality used in this patient. When the patient re-presented three months later, the site was healing well and there was minimal scarring (Figure 4).

\section{QUESTION 6}

What are the benefits of curettage and cautery?

\section{ANSWER 6}

Curettage and cautery involves skin lesions being scraped off with a curette, followed by light cautery and a further round of curettage and cautery. As a method of treatment, it has a short healing time, few complications and good functional and cosmetic outcomes. ${ }^{9}$ Unlike topical chemotherapeutic agents, it does not depend on patient compliance and does not cause irritation of the surrounding skin. Curettage therapy has a high cure rate in the hands of an experienced operator. 9,10 When compared with laser therapy and photodynamic therapy, it requires less specialised equipment and can be readily performed in a general practice setting.

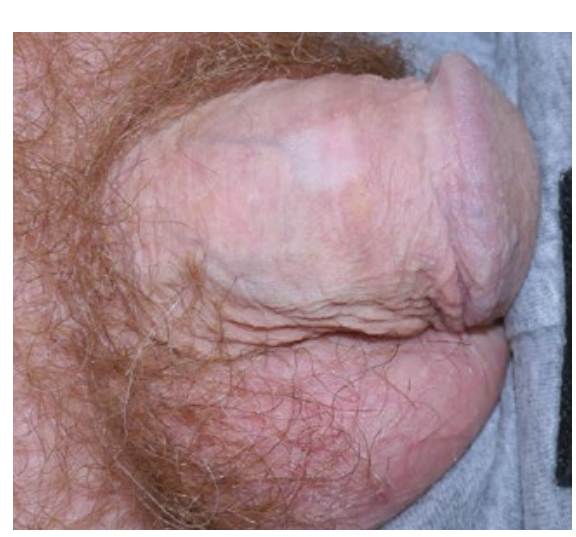

Figure 4. Good healing and cosmetic outcomes with minimal scarring after three months

\section{Key points}

- Differential diagnoses of solitary penile lesions are broad.

- Curettage is a biopsy method for penile lesions.

- Multiple treatment modalities are available for bowenoid papulosis, including surgery, laser and topical chemotherapy.

\section{Authors}

Cong Sun BSc, MD, Resident Medical Officer, Princess Alexandra Hospital, Woolloongabba, Qld Jim Muir MBBS, FACD, Consultant Dermatologist, Mater Hospital, South Brisbane, Qld

Funding: None

Competing interests: None

Provenance and peer review: Not commissioned, externally peer reviewed.

Correspondence to:

tom.cong.sun@gmail.com

\section{Acknowledgements}

The authors thank the patient for his permission to use his clinical information for this article.

\section{References}

1. Arya M, Kalsi J, Kelly J, Muneer A. Malignant and premalignant lesions of the penis. BMJ 2013;346:f1149. doi: 10.1136/bmj.f1149.

2. David N, Tang A. Efficacy and safety of penile biopsy in a GUM clinic setting. Int J STD AIDS 2002:13(8):573-76. doi: 10.1258/095646202760159729.

3. Fortier E, Cerruti A, Clec'h CL, Bigot P. Review of cutaneous penile lesions. J Clin Urol 2018;11(6):429-39.

4. Chan SL, Watchorn RE, Panagou E, et al. Dermatoscopic findings of penile intraepithelial neoplasia: Bowenoid papulosis, Bowen disease and erythroplasia of Queyrat. Australas J Dermatol 2019;60(3):e201-07. doi: 10.1111/ajd.12981.
5. Gabrielson AT, Le TV, Fontenot C, Usta M, Hellstrom WJG. Male genital dermatology: A primer for the sexual medicine physician. Sex Med Rev 2019;7(1):71-83. doi: 10.1016/j. sxmr.2018.09.004.

6. Hsu GL, Hsieh $\mathrm{CH}$, Chen HS, et al. The advancement of pure local anesthesia for penile surgeries: Can an outpatient basis be sustainable? J Androl 2007;28(1):200-05. doi: 10.2164/ jandrol.106.000679.

7. Kouba DJ, LoPiccolo MC, Alam M, et al. Guidelines for the use of local anesthesia in office-based dermatologic surgery. J Am Acad Dermatol 2016;74(6):1201-19. doi: 10.1016/j.jaad.2016.01.022.

8. Schwartz RA, Janniger CK. Bowenoid papulosis. J Am Acad Dermatol 1991;24(2 Pt 1):261-64. doi: 10.1016/0190-9622(91)70039-5.

9. Ahmed I, Berth-Jones J, Charles-Holmes S, O'Callaghan CJ, Ilchyshyn A. Comparison of cryotherapy with curettage in the treatment of Bowen's disease: A prospective study. $\mathrm{Br} J$ Dermatol 2000;143(4):759-66. doi: 10.1046/j.13652133.2000.03772.x

10. Sheridan AT, Dawber RP. Curettage, electrosurgery and skin cancer. Australas Dermatol 2000;41(1):19-30. doi: 10.1046/j.14400960.2000.00383.x. 